\title{
Soluble Receptor of Advanced Glycated Endproducts Is Associated With Plaque Vulnerability in Patients With Acute Myocardial Infarction
}

\author{
Hun-Jun Park, MD; Ju-Yeol Baek, MD; Woo Seung Shin, MD; Dong-Bin Kim, MD; \\ Sung Won Jang, MD; Dong Il Shin, MD; Yoon Seok Koh, MD; Suk Min Seo, MD; \\ Jae-Sun Uhm, MD; Tae Hoon Kim, MD; Chan Joon Kim, MD; \\ Pum Joon Kim, MD; Kiyuk Chang, MD; Wook Sung Chung, MD; \\ Ki-Bae Seung, MD; Jong Min Lee, MD
}

\begin{abstract}
Background: The roles of soluble and endogenous secretory receptors for advanced glycation endproducts (sRAGE and esRAGE, respectively) in plaque vulnerability are unknown in patients with acute myocardial infarction (AMI).
\end{abstract}

\begin{abstract}
Methods and Results: We enrolled 54 patients with AMI (27 patients had type 2 diabetes mellitus [DM]) who had undergone primary percutaneous coronary intervention, and 54 controls who were matched for age, gender and the presence of DM. Plasma levels of s/esRAGE and matrix metalloproteinase (MMP)-9 were measured at the time of coronary angiography. There were no significant differences in the baseline characteristics of the AMI and control groups, except for the C-reactive protein levels (CRP: $14.1 \pm 14.2 \mathrm{mg} / \mathrm{L}$ vs. $3.7 \pm 5.2 \mathrm{mg} / \mathrm{L}, \mathrm{P}<0.001$ ). The plasma levels of MMP-9 (28.6 \pm 21.4 vs. $14.3 \pm 8.5 \mathrm{ng} / \mathrm{ml} P<0.001)$ and SRAGE $(0.61 \pm 0.28$ vs. $0.41 \pm 0.17 \mathrm{ng} / \mathrm{ml}, P<0.001)$ were higher in the AMI group than in the controls. In multivariate logistic regression analysis, the plasma levels of MMP-9 and SRAGE above the median (odds ratio [OR], 2.39; 95\% confidence interval [CI], 1.02-5.58; $\mathrm{P}=0.044$; $\mathrm{OR}, 2.47 ; 95 \% \mathrm{Cl}, 1.05-5.80 ; \mathrm{P}=0.039$, respectively) were independent predictors of $\mathrm{AMI}$, as well as being a current smoker (OR, 2.98; 95\%Cl, 1.18-7.55; $\mathrm{P}=0.021$ ) and $\mathrm{CRP} \geq 3.0 \mathrm{mg} / \mathrm{L}(\mathrm{OR}, 3.08 ; 95 \% \mathrm{Cl}, 1.25-7.59 ; \mathrm{P}=0.015)$.
\end{abstract}

Conclusions: An elevated plasma level of sRAGE might be independently associated with plaque vulnerability, as well as MMP-9, in patients with AMI. (Circ J 2011; 75: 1685-1690)

Key Words: Acute myocardial infarction; Matrix metalloproteinase-9; Plaque vulnerability; Soluble receptor for advanced glycation endproducts

$\mathbf{P}$ laque rupture is the main cause of acute myocardial infarction (AMI). ${ }^{1,2}$ The immediate site of the rupture is always marked by an inflammatory process, which suggests that inflammation plays a role in destabilizing the fibrous cap and thus in enhancing the risk of coronary thrombosis. ${ }^{3}$ Previous reports are that increased macrophage density and/or activation in the atherosclerotic plaque may induce collagen breakdown in the fibrous cap by secreting matrix metalloproteinases (MMPs), and possibly other proteases, thus contributing to the plaque's vulnerability to rupture. ${ }^{4-6}$
Diabetes mellitus (DM) is associated with a higher incidence of AMI. The relative risk of incident of AMI is increased 2-3-fold in those with type $2 \mathrm{DM}$, and the risk of death is increased 2-fold, independent of other risk factors of coronary artery disease (CAD). ${ }^{7}$ The possible mechanism involves enhanced cellular oxidant stress by the interaction of advanced glycation endproducts (AGEs) with their receptors (RAGE), which may quench nitric oxide through the generation of oxygen free radicals, leading to impaired endothelial function, leukocyte adhesion, platelet aggregation,

Received December 14, 2010; revised manuscript received January 25, 2011; accepted March 1, 2011; released online May 17, 2011 Time for primary review: 10 days

Department of Cardiology, College of Medicine, Seoul St Mary's Hospital, The Catholic University of Korea, Seoul (H.-J.P., S.M.S., J.-S.U., T.H.K., C.J.K., P.J.K., K.C., W.S.C., K.-B.S.); Department of Cardiology, College of Medicine, Daejeon St Mary's Hospital, The Catholic University of Korea, Daejeon (J.-Y.B.); Department of Cardiology, College of Medicine, Uijeongbu St Mary's Hospital, The Catholic University of Korea, Uijeongbu (W.S.S., Y.S.K., J.M.L.); Department of Cardiology, College of Medicine, St Paul's Hospital, The Catholic University of Korea, Seoul (D.-B.K., S.W.J.); and Department of Cardiology, College of Medicine, Incheon St Mary's Hospital, The Catholic University of Korea, Incheon (D.I.S.), Korea

The first two authors contributed equally to this work (H.-J.P., J.-Y.B.).

Mailing address: Jong Min Lee, MD, Associate Professor, Department of Cardiology, College of Medicine, Uijeongbu St Mary's Hospital,

The Catholic University of Korea, 65-1, Geumo-dong, Uijeongbu, Gyeonggi-do, Republic of Korea. E-mail: cardioman70@gmail.com

ISSN-1346-9843 doi:10.1253/circj.CJ-10-1248

All rights are reserved to the Japanese Circulation Society. For permissions, please e-mail: cj@j-circ.or.jp 


\begin{tabular}{|c|c|c|c|}
\hline & $\begin{array}{c}\text { AMI } \\
(n=54)\end{array}$ & $\begin{array}{c}\text { Control } \\
(n=54)\end{array}$ & $P$ value \\
\hline \multicolumn{4}{|l|}{ Clinical variables } \\
\hline Age, years & $64.2 \pm 13.1$ & $62.2 \pm 12.0$ & 0.396 \\
\hline Male sex, n (\%) & $27(50.0)$ & $27(50.0)$ & 1.000 \\
\hline $\mathrm{BMI}, \mathrm{kg} / \mathrm{m}^{2}$ & $23.8 \pm 2.6$ & $24.9 \pm 3.6$ & 0.084 \\
\hline Hypertension, n (\%) & 28 (51.9) & $29(53.7)$ & 0.847 \\
\hline Diabetes mellitus, n (\%) & $27(50.0)$ & $27(50.0)$ & 1.000 \\
\hline Hyperlipidemia, n (\%) & $11(20.4)$ & $7(13.0)$ & 0.302 \\
\hline Current smoking, n (\%) & $24(44.4)$ & $15(27.8)$ & 0.071 \\
\hline \multicolumn{4}{|l|}{ Laboratory variables } \\
\hline Hemoglobin, g/dl & $13.8 \pm 1.7$ & $13.2 \pm 1.9$ & 0.124 \\
\hline $\mathrm{Cr}, \mathrm{mg} / \mathrm{dl}$ & $1.01 \pm 0.36$ & $0.99 \pm 0.42$ & 0.860 \\
\hline $\mathrm{TC}, \mathrm{mg} / \mathrm{dl}$ & $177.5 \pm 48.1$ & $178.4 \pm 42.2$ & 0.923 \\
\hline $\mathrm{TG}, \mathrm{mg} / \mathrm{dl}$ & $139.5 \pm 83.0$ & $154.1 \pm 103.2$ & 0.422 \\
\hline $\mathrm{HDL}, \mathrm{mg} / \mathrm{dl}$ & $43.3 \pm 9.3$ & $44.1 \pm 11.8$ & 0.708 \\
\hline LDL, mg/dl & $106.0 \pm 42.3$ & $107.0 \pm 33.0$ & 0.900 \\
\hline $\mathrm{HbA}_{1 c}, \%$ & $6.9 \pm 1.6$ & $7.1 \pm 1.9$ & 0.643 \\
\hline $\mathrm{CRP}, \mathrm{mg} / \mathrm{L}$ & $14.1 \pm 14.2$ & $3.7 \pm 5.2$ & $<0.001$ \\
\hline \multicolumn{4}{|l|}{ Medications, n (\%) } \\
\hline Aspirin & $15(27.8)$ & $17(31.5)$ & 0.673 \\
\hline$\beta$-blocker & $8(14.8)$ & $9(16.7)$ & 0.792 \\
\hline ACEI/ARB & $16(29.6)$ & 18 (33.3) & 0.679 \\
\hline CCB & $21(38.9)$ & $14(25.9)$ & 0.150 \\
\hline Statin & 7 (13.0) & $6(11.1)$ & 0.767 \\
\hline $\mathrm{OHA}$ & $23(42.6)$ & $22(40.7)$ & 0.845 \\
\hline Insulin & $6(11.1)$ & $4(7.4)$ & 0.507 \\
\hline
\end{tabular}

$\mathrm{AMI}$, acute myocardial infarction; $\mathrm{BMI}$, body mass index; $\mathrm{Cr}$, creatinine; TC, total cholesterol; TG, triglycerides; HDL, high-density lipoprotein; LDL, low-density lipoprotein; $\mathrm{HbA}_{1 \mathrm{c}}$, glycosylated hemoglobin; CRP, C-reactive protein; ACEI/ARB, angiotensinconverting enzyme inhibitor/angiotensin II receptor blocker; CCB, calcium-channel blocker; OHA, oral hypoglycemic agent.

and cytokine expression, resulting in macrophage infiltration at the site of atherosclerotic plaques and increased plaque vulnerability. ${ }^{8,9}$

Soluble forms of RAGE appear in the plasma as spliced variants (endogenous secretory receptor for AGE [esRAGE]) leaking through the transmembrane and cytosolic domain, ${ }^{10}$ and as a proteolytically cleaved form of RAGE (sRAGE), which is most probably shed into the circulation by proteolytic processing of the sheddase a disintegrin and metalloproteinase 10 (ADAM 10). ${ }^{11}$ Although they may reflect the activity of the AGE-RAGE axis and act as decoys that neutralize the actions of AGEs in the circulation, ${ }^{12-14}$ the functional role of these soluble forms of RAGE in plaque vulnerability remains unclear in patients with AMI.

In this study, we measured the plasma levels of MMP-9, sRAGE, and esRAGE in AMI patients to evaluate the biological effects of these molecules on plaque vulnerability.

\section{Methods}

\section{Patient Selection}

Of 1,282 patients who underwent coronary angiography (CAG) between October 2007 and December 2008 at Seoul St Mary's Hospital, we enrolled 54 patients with AMI (27 patients had type $2 \mathrm{DM}$ ) who underwent primary percutaneous coronary intervention (PCI) within $12 \mathrm{~h}$ of the onset of chest pain. As a control group, we selected 54 patients with normal CAG who were matched for age, gender, and the presence of DM.

AMI was diagnosed based on chest pain persisting for $30 \mathrm{~min}$ and elevation of the serum creatine kinase (CK-MB) level to more than twice the upper limit of normal. Patients with ST elevation MI (STEMI) and non-STEMI (NSTEMI) were included in this study. DM was diagnosed by demonstrating any one of the following: (1) symptoms of hyperglycemia and a random plasma glucose $\geq 200 \mathrm{mg} / \mathrm{dl}$; (2) fasting plasma glucose level $\geq 126 \mathrm{mg} / \mathrm{dl}$; and (3) plasma glucose $\geq 200 \mathrm{mg} / \mathrm{dl}$ at $2 \mathrm{~h}$ after a $75-\mathrm{g}$ oral glucose load in a glucose tolerance test. ${ }^{15}$

We excluded patients who had comorbidities, such as acute and/or chronic infections, inflammatory diseases, malignancies, ongoing liver disease and/or abnormal liver function tests (serum aspartate aminotransferase or alanine aminotransferase $>3$-fold the upper limit of normal), and renal insufficiency (serum creatinine $>2.5 \mathrm{mg} / \mathrm{dl}$ ).

\section{Data Collection and Factor Measurements}

Clinical, laboratory, and medication histories were obtained through a comprehensive review of each patient's medical records, including case notes from the hospital's computerized patient information system. Hypertension was defined as systolic blood pressure $\geq 140 \mathrm{mmHg}$, diastolic blood pressure $\geq 90 \mathrm{mmHg}$ and/or use of antihypertensive drugs. Hyperlipidemia was defined as total cholesterol level $\geq 240 \mathrm{mg} / \mathrm{dl}$ or triglyceride level $\geq 200 \mathrm{mg} / \mathrm{dl}$, and/or the use of any relevant drugs. Current smoking referred to the active use of tobacco products at the time of enrollment in the study. Hemoglobin, serum creatinine, fasting lipid profiles, and levels of glycosylated hemoglobin $\left(\mathrm{HbA}_{1 \mathrm{c}}\right)$ and $\mathrm{C}$-reactive protein (CRP) were obtained at the time of CAG. Plasma levels of MMP-9, sRAGE (R\&D Systems, Minneapolis, MN, USA) and esRAGE (B-Bridge International, Sunnyvale, CA, USA) were measured by enzyme-linked immunosorbent assays using the blood samples obtained from each patient through the introducer sheath placed in the femoral artery at the time of CAG. Informed consent was given by each patient and the study protocol was approved by the institutional review board of Seoul St Mary's Hospital, Catholic University of Korea.

\section{Statistical Analysis}

Analysis of categorical data to identify statistically significant differences between groups was performed using the chi-square test. Continuous variables are presented as the mean \pm standard deviation and were compared by Student's t-test or 1-way ANOVA. To identify independent predictors of AMI, both uni- and multivariate logistic regression analyses were performed for these subjects. Covariates statistically significant on univariate analysis $(\mathrm{P}<0.1)$ were considered as candidate variables in the multivariate models. Statistical analyses were performed with SPSS (version 15.0; SPSS Inc, Chicago, IL, USA). For all analyses, $\mathrm{P}<0.05$ was considered statistically significant.

\section{Results}

Table 1 shows the baseline characteristics of the AMI group and controls at the time of CAG. There were no significant differences between the groups, with the exception of the serum CRP level $(14.1 \pm 14.2$ vs. $3.7 \pm 5.2 \mathrm{mg} / \mathrm{L}, \mathrm{P}<0.001)$. The body mass index was lower and the proportion of current smokers was higher in the AMI group than in the controls, 

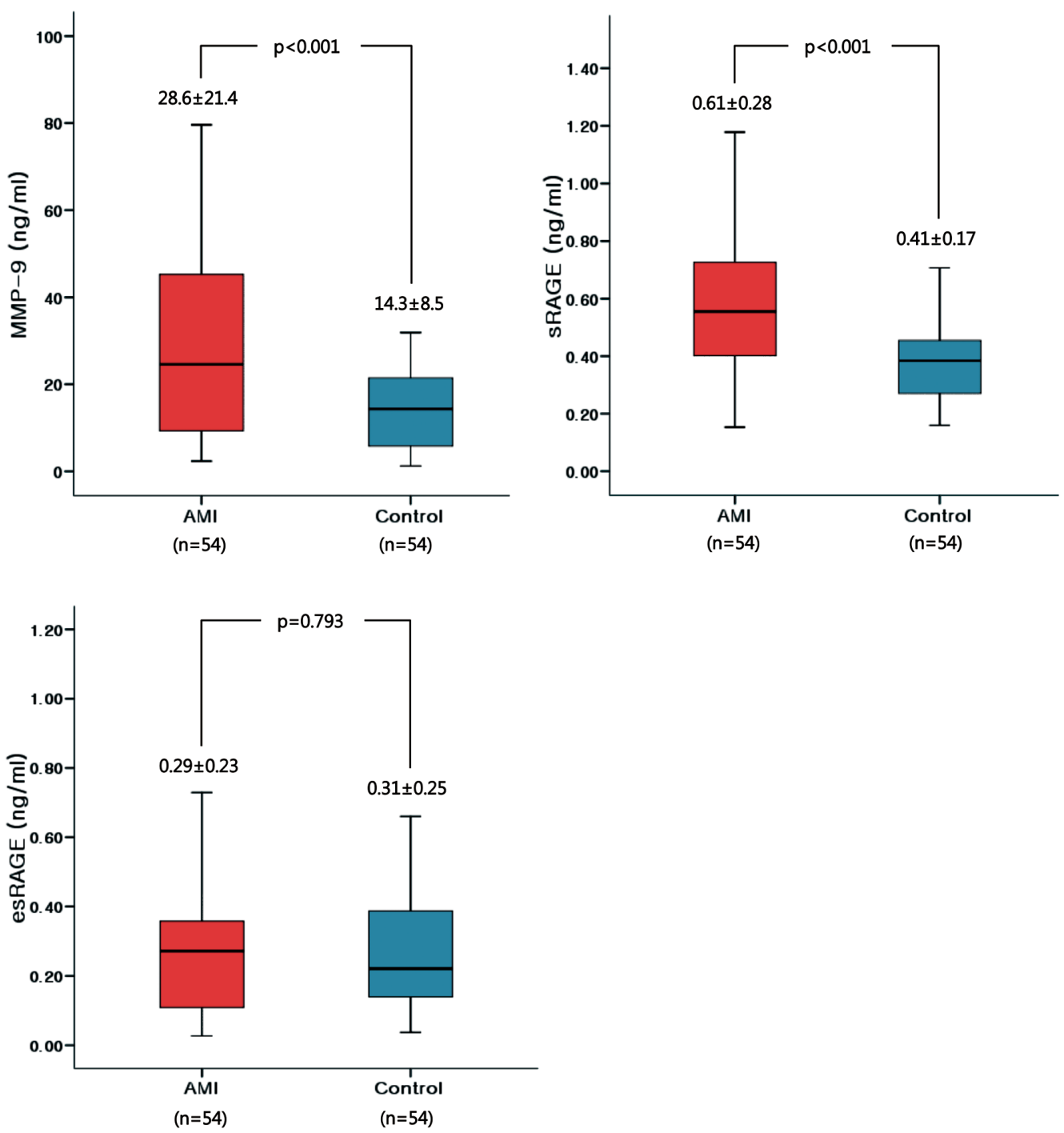

Figure 1. Comparison of the plasma levels of MMP-9 and s/esRAGE in the AMI group and controls. AMI, acute myocardial infarction; MMP, matrix metalloproteinases; s/esRAGE, soluble/endogenous secretory receptors for advanced glycation endproducts.

although statistically insignificant.

The plasma levels of MMP-9 $(28.6 \pm 21.4$ vs. $14.3 \pm 8.5 \mathrm{ng} / \mathrm{ml}$, $\mathrm{P}<0.001)$ and $\operatorname{SRAGE}(0.61 \pm 0.28$ vs. $0.41 \pm 0.17 \mathrm{ng} / \mathrm{ml}, \mathrm{P}<0.001)$ were higher in the AMI group than in the controls. However, the plasma level of esRAGE was similar between the groups $(0.29 \pm 0.23$ vs. $0.31 \pm 0.25 \mathrm{ng} / \mathrm{ml}, \mathrm{P}=0.793$; Figure 1$)$. In subgroup analysis according to the presence of DM, the plasma levels of MMP-9 and sRAGE were also higher in the AMI group than in the controls, regardless of the presence of DM (Figure 2).

Table 2 gives the odds ratios (ORs) of AMI in patients with prespecified risk factors at the time of the CAG. Based on univariate logistic regression analysis, a plasma level of CRP $\geq 3.0 \mathrm{mg} / \mathrm{L}$, and MMP-9 and sRAGE levels above the median were significant independent predictors of AMI $(\mathrm{P}<0.05)$. Current smokers were also identified in a broader range of variables $(\mathrm{P}<0.1)$ that might be associated with AMI. Based on multiple logistic regression analysis, plasma levels of MMP-9 and sRAGE above the median (OR, 2.39; 95\% confidence interval $[\mathrm{CI}], 1.02-5.58 ; \mathrm{P}=0.044$; and $\mathrm{OR}, 2.47$; $95 \% \mathrm{CI}, 1.05-5.80 ; \mathrm{P}=0.039$, respectively) were significantly associated with AMI, as well as being a current smoker (OR, $2.98 ; 95 \% \mathrm{CI}, 1.18-7.55 ; \mathrm{P}=0.021)$ and having a $\mathrm{CRP} \geq 3.0 \mathrm{mg} / \mathrm{L}$ (OR, 3.08; 95\%CI, 1.25-7.59; $\mathrm{P}=0.015)$.

\section{Discussion}

In the present study, we report that plasma levels of MMP-9 and sRAGE were significantly higher in the AMI group than in the controls, independent of the presence of DM. However, plasma levels of esRAGE showed no differences between the groups. Moreover, plasma levels of MMP-9 and sRAGE above the median were significant predictors of AMI, as well as being a current smoker and having a CRP level $\geq 3.0 \mathrm{mg} / \mathrm{L}$. These findings suggest that the plasma level of sRAGE is positively associated with AMI and that RAGE-dependent inflammatory responses might contribute to plaque vulnerability, along with MMP-9. This is the first report to evaluate 

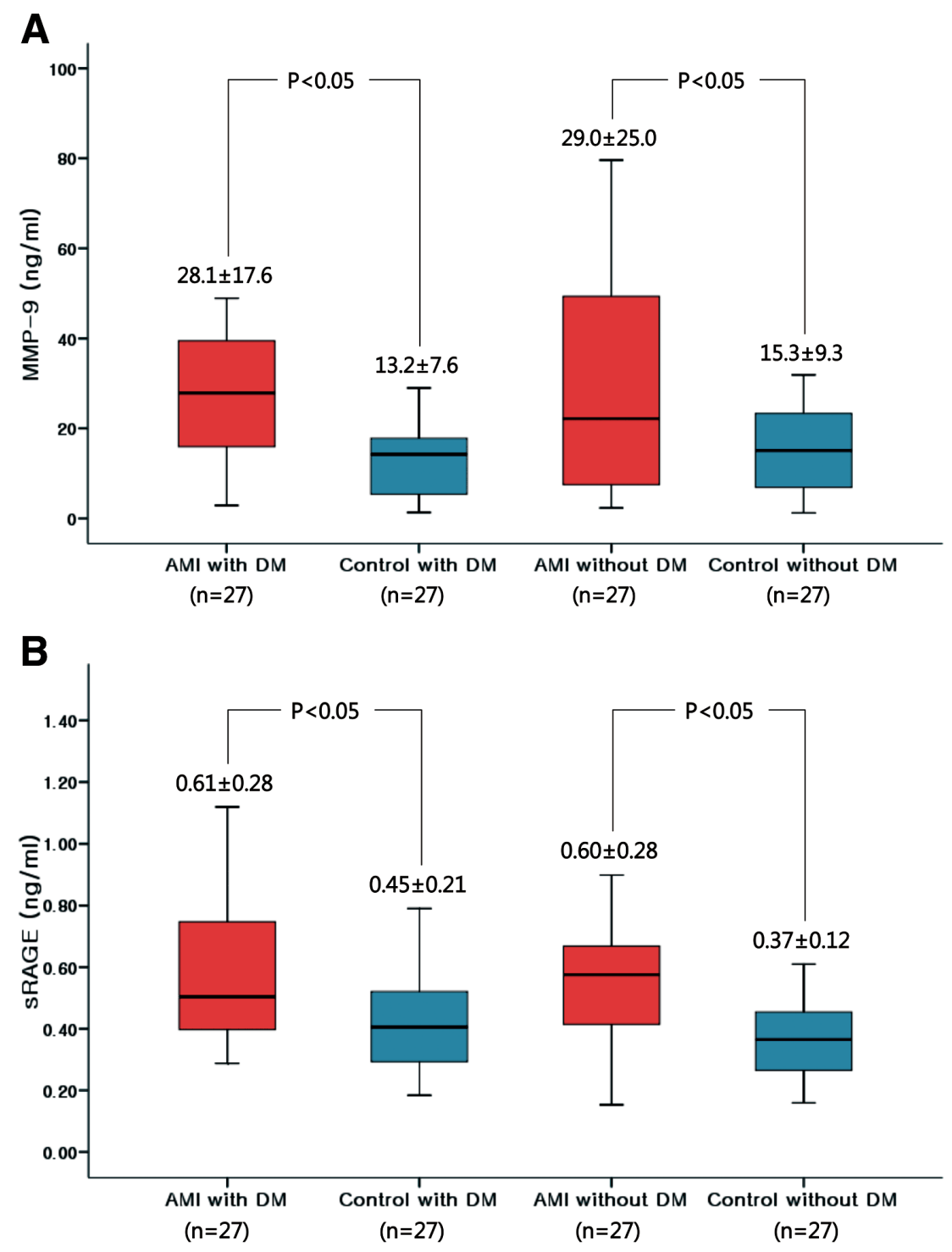

Figure 2. Subgroup analysis of the plasma levels of MMP-9 (A) and SRAGE (B) between the AMI group and controls according to the presence of DM (post hoc analysis by Tukey test). AMI, acute myocardial infarction; DM, diabetes mellitus; MMP, matrix metalloproteinases; sRAGE, soluble secretory receptors for advanced glycation endproducts.

the biological roles of sRAGE in AMI patients who have undergone primary PCI.

An AMI is thought to be the result of an under-exaggerated inflammatory state that destabilizes the fibrous cap tissue and thus enhances the risk of coronary thrombosis. ${ }^{3}$ MMPs are significant cytokines, mainly produced by infiltrating inflammatory cells and can degrade the strength-giving collagens and other structural proteins of the arterial extracellular matrix. Overproduction of MMPs by monocytes/macrophages could therefore promote rupture of atherosclerotic plaque rupture and subsequent MI. ${ }^{16}$ Among the various MMPs, MMP-9 may play an important role in plaque rupture because of its broad substrate specificity and its position in the matrix proteolytic cascade. ${ }^{17}$ Some clinical studies have reported that MMP-9 is significantly elevated in patients with acute coronary syndrome, including AMI. ${ }^{18,19}$ a recent virtual histology intravascular ultrasound study also showed that the plasma MMP-9 level was increased in patients with multiple ruptured plaques, as well as in patients with a ruptured plaque among the culprit lesions. ${ }^{20}$ Consistent with previous reports, our data also showed that the plasma level of MMP-9 was significantly higher in the AMI group than in the controls.

The CRP level, which is a marker of underlying systemic inflammation, is also an independent clinical predictor of plaque rupture in AMI patients. In a pathologic study, using immunohistochemical staining for CRP, of patients who died suddenly associated with severe CAD has reported that CRP may correlate with the number of thin-capped fibroatheromas, which can be considered as vulnerable plaque. ${ }^{21}$ Several IVUS studies also have showed that ruptured plaque and/or vulnerable plaque exist not only at the culprit lesion but also in a pan-coronary artery setting in patients with AMI and elevated CRP level. ${ }^{22-24}$ Recently, Kashiwagi et al reported that positive arterial remodeling in IVUS, a thin fibrous cap thickness in optical coherence tomography, and a high CRP level were associated with each other in patients with acute coronary syndrome. ${ }^{25}$ Their findings are consistent with our results that the serum CRP level was significantly higher in the AMI group than in the controls, and an elevated CRP level ( $\geq 3 \mathrm{mg} / \mathrm{L})$ was an independent predictor of AMI.

Recent clinical studies have investigated the potential significance of circulating sRAGE and esRAGE concentrations 


\begin{tabular}{|c|c|c|c|c|c|c|}
\hline \multirow[b]{3}{*}{ Clinical variables } & \multicolumn{3}{|c|}{ Univariate } & \multicolumn{3}{|c|}{ Multivariate } \\
\hline & OR & $95 \% \mathrm{Cl}$ & $P$ value & OR & $95 \% \mathrm{Cl}$ & $P$ value \\
\hline & & & & & & \\
\hline Age $\geq 65$ years & 1.16 & $0.55-2.47$ & 0.700 & & & \\
\hline $\mathrm{BMI} \geq 25 \mathrm{~kg} / \mathrm{m}^{2}$ & 0.59 & $0.27-1.27$ & 0.173 & & & \\
\hline Hypertension & 0.93 & $0.44-1.98$ & 0.847 & & & \\
\hline Hyperlipidemia & 1.72 & $0.61-4.83$ & 0.305 & & & \\
\hline Current smoker & 2.08 & $0.93-4.64$ & 0.073 & 2.98 & $1.18-7.55$ & 0.021 \\
\hline \multicolumn{7}{|l|}{ Laboratory variables } \\
\hline Hemoglobin <12 g/dl & 1.92 & $0.69-5.32$ & 0.211 & & & \\
\hline eGFR $<60 \mathrm{ml} \cdot \mathrm{min} \cdot 1.73 \mathrm{~m}^{2}$ & 1.15 & $0.41-3.25$ & 0.792 & & & \\
\hline $\mathrm{TC} \geq 240 \mathrm{mg} / \mathrm{dl}$ & 1.59 & $0.34-7.50$ & 0.560 & & & \\
\hline$T G \geq 200 \mathrm{mg} / \mathrm{dl}$ & 0.89 & $0.38-2.08$ & 0.782 & & & \\
\hline $\mathrm{HDL}<40 \mathrm{mg} / \mathrm{dl}$ & 0.93 & $0.40-2.12$ & 0.856 & & & \\
\hline $\mathrm{LDL} \geq 130 \mathrm{mg} / \mathrm{dl}$ & 1.53 & $0.55-4.27$ & 0.419 & & & \\
\hline $\mathrm{CRP} \geq 3.0 \mathrm{mg} / \mathrm{L}$ & 3.14 & $1.43-6.91$ & 0.004 & 3.08 & $1.25-7.59$ & 0.015 \\
\hline $\mathrm{HbA}_{1 \mathrm{c}} \geq 7.0 \%$ & 0.55 & $0.18-1.66$ & 0.286 & & & \\
\hline MMP-9 $\geq$ median cut-off & 2.47 & $1.14-5.35$ & 0.022 & 2.39 & $1.02-5.58$ & 0.044 \\
\hline sRAGE $\geq$ median cut-off & 3.13 & $1.43-6.87$ & 0.004 & 2.47 & $1.05-5.80$ & 0.039 \\
\hline
\end{tabular}

OR, odd ratio; $\mathrm{Cl}$, confidence interval; eGFR, estimated glomerular filtration rate by Modification of Diet in Renal Disease (MDRD) formula; MMP-9, matrix metalloproteinase-9; sRAGE, soluble receptor of advanced glycated endproducts. Other abbreviations see in Table 1.

in several pathologic conditions, particularly atherosclerotic vascular disease. ${ }^{26-29}$ In CAD, some clinical studies have shown that a lower level of plasma sRAGE is inversely associated with the severity of CAD. ${ }^{28,29}$ However, other reports have shown that serum sRAGE levels are significantly higher in patients with type $2 \mathrm{DM}$ than in non-diabetic subjects, and positively associated with the presence of CAD. ${ }^{30}$ The same authors also demonstrated that the sRAGE level positively correlated with circulating levels of AGEs and soluble forms of vascular cell adhesion molecule-1, suggesting that the sRAGE level may be elevated in response to circulating AGEs, thereby constituting a novel marker of vascular injury in patients with DM. ${ }^{31}$ In the present study, we demonstrated that the plasma level of sRAGE was positively associated with AMI, but not that of esRAGE. These findings suggested that in patients with an AMI, an enhanced AGE-RAGE interaction may increase the inflammatory response in vulnerable plaques, together with plasma levels of sRAGE, but it does not efficiently capture or eliminate circulating AGEs in vivo by acting as a decoy receptor. ${ }^{32}$ In addition, sRAGE and esRAGE may exert different biological effects on plaque vulnerability in patients with AMI, even though they may act in a very similar way as decoys that neutralize the actions of AGEs. In fact, the endogenous action of sRAGE may not be confined to a decoy function against RAGE signaling. Pullerits et al reported that sRAGE interacts with Mac-1 and is mediated via nuclear factor- $\kappa \mathrm{B}$ to act as important pro-inflammatory and chemotactic molecules in an HMGB1-induced arthritis model. ${ }^{33}$

Interestingly, in a subgroup analysis of our study patients with AMI, there were no significant correlations between the plasma levels of MMP-9 and sRAGE $(\mathrm{r}=-0.080, \mathrm{P}=0.563)$ or those of CRP and sRAGE ( $\mathrm{r}=0.022, \mathrm{P}=0.877)$. This finding was inconsistent with a recent study that showed sRAGE was negatively correlated with MMP-9 $(\mathrm{r}=-0.419, \mathrm{P}<0.01)$ and CRP $(\mathrm{r}=-0.326, \mathrm{P}<0.01)$ in non-diabetic patients with premature $\mathrm{CAD} .{ }^{29}$ The difference in the results might be caused by the different clinical settings of AMI and premature CAD. Unlike MMP-9 and CRP, sRAGE may have dual functions as a decoy and/or trigger of inflammation, and the net effect of sRAGE and its ligand interactions can be antior pro-inflammatory depending on the inflammatory milieu. ${ }^{33}$ In the disease subset of AMI, the role of sRAGE may outweigh its pro-inflammatory properties, even though the decoy function of SRAGE may attenuate the positive correlation with MMP-9 and CRP to some degree. However, further studies are needed to provide more clarity about the biological mechanisms underlying the kinetics of sRAGE production and removal in both health and disease states.

In conclusion, the plasma level of sRAGE was significantly higher in the AMI group than in the controls, and this elevated sRAGE concentration may be independently associated with plaque vulnerability in patients with AMI.

\section{Study Limitations}

First, this study was a case-control design and examined a relatively small number of subjects, despite the selection of the control group after matching for age, gender, and the presence of DM. Therefore, it was difficult to identify a cause and effect relationship between MMP-9 and sRAGE on plaque vulnerability in the current study. Second, we were unable to measure plasma concentrations of AGEs and/or tissue RAGE expression, which could provide a better understanding of the relationship between the activities of the AGE-RAGE axis, the soluble forms of RAGE, and AMI. Finally, plaque rupture is a local event that develops in highly inflamed vulnerable plaque in human coronary arteries. Therefore, associated molecules may be increased or attenuated in the local milieu, but we used blood samples obtained from each patient when the introducer sheath was placed in the femoral artery at the time of the index procedure. Samples taken from this location may not necessarily demonstrate a gradient because of dilution and washout effects. 


\section{References}

1. Virmani R, Kolodgie FD, Burke AP, Farb A, Schwartz SM. Lessons from sudden coronary death: A comprehensive morphological classification scheme for atherosclerotic lesions. Arterioscler Thromb Vasc Biol 2000; 20: $1262-1275$.

2. Falk E, Shah PK, Fuster V. Coronary plaque disruption. Circulation 1995; 92: 657-671.

3. van der Wal AC, Becker AE, van der Loos CM, Das PK. Site of intimal rupture or erosion of thrombosed coronary atherosclerotic plaques is characterized by an inflammatory process irrespective of the dominant plaque morphology. Circulation 1994; 89: 36-44.

4. Shah PK, Falk E, Badimon JJ, Fernandez-Ortiz A, Mailhac A, Villareal-Levy G, et al. Human monocyte-derived macrophages induce collagen breakdown in fibrous caps of atherosclerotic plaques: Potential role of matrix- degrading metalloproteinases and implications for plaque rupture. Circulation 1995; 92: 1565-1569.

5. Choudhary S, Higgins CL, Chen IY, Reardon M, Lawrie G, Vick GW 3rd, et al. Quantitation and localization of matrix metalloproteinases and their inhibitors in human carotid endarterectomy tissues. Arterioscler Thromb Vasc Biol 2006; 26: 2351-2358.

6. Sluijter JP, Pulskens WP, Schoneveld AH, Velema E, Strijder CF, Moll F, et al. Matrix metalloproteinase 2 is associated with stable and matrix metalloproteinases 8 and 9 with vulnerable carotid atherosclerotic lesions: A study in human endarterectomy specimen pointing to a role for different extracellular matrix metalloproteinase inducer glycosylation forms. Stroke 2006; 37: 235-239.

7. Almdal T, Scharling H, Jensen JS, Vestergaard H. The independent effect of type 2 diabetes mellitus on ischemic heart disease, stroke, and death: A population based study of 13,000 men and women with 20 years of follow-up. Arch Intern Med 2004; 164: 14221426.

8. Yan SD, Schmidt AM, Anderson GM, Zhang J, Brett J, Zou YS, et al. Enhanced cellular oxidant stress by the interaction of advanced glycation endproducts with their receptors/binding proteins. J Biol Chem 1994; 269: 9889-9897.

9. Nesto RW, Zarich S. Acute myocardial infarction in diabetes mellitus: Lessons learned from ACE inhibition. Circulation 1998; 97: $12-15$.

10. Hudson BI, Carter AM, Harja E, Kalea AZ, Arriero M, Yang H, et al. Identification, classification, and expression of RAGE gene splice variants. FASEB J 2008; 22: $1572-1580$.

11. Raucci A, Cugusi S, Antonelli A, Barabino SM, Monti L, Bierhaus A, et al. A soluble form of the receptor for advanced glycation endproducts (RAGE) is produced by proteolytic cleavage of the membrane-bound form by sheddase a disintegrin and metalloprotease 10 (ADAM10). FASEB J 2008; 22: 3716-3727.

12. Geroldi D, Falcone C, Emanuele E. Soluble receptor for advanced glycation endproducts: From disease marker to potential therapeutic target. Curr Med Chem 2006; 13: $1971-1978$.

13. Yamagishi S, Matsui T, Nakamura K. Kinetics, role and therapeutic implications of endogenous soluble form of receptor for advanced glycation endproducts (sRAGE) in diabetes. Curr Drug Targets 2007; 8: 1138-1143.

14. Yamagishi S, Matsui T. Soluble form of a receptor for advanced glycation endproducts (sRAGE) as a biomarker. Front Biosci 2010; 2: $1184-1195$.

15. Expert Committee on the Diagnosis and Classification of Diabetes Mellitus. Report of the expert committee on the diagnosis and classification of diabetes mellitus. Diabetes Care 2003; 26: S5-S20.

16. Newby AC. Metalloproteinases and vulnerable atherosclerotic plaques. Trends Cardiovasc Med 2007; 17: 253-258.

17. Brown DL, Hibbs MS, Kearney M, Loushin C, Isner JM. Identification of $92-\mathrm{Kd}$ gelatinase in human coronary atherosclerotic lesions: Association of active enzyme synthesis with unstable angina. Circulation 1995; 91: 2125-2131.
18. Kai H, Ikeda H, Yasukawa H, Kai M, Seki Y, Kuwahara F, et al. Peripheral blood levels of matrix metalloproteases-2 and -9 are elevated in patients with acute coronary syndromes. J Am Coll Cardiol 1998; 32: 368-372.

19. Funayama H, Ishikawa SE, Kubo N, Katayama T, Yasu T, Saito M, et al. Increases in interleukin-6 and matrix metalloproteinase- 9 in the infarct-related coronary artery of acute myocardial infarction. Circ J 2004; 68: $451-454$.

20. Park JP, Lee BK, Shim JM, Kim SH, Lee CW, Kang DH, et al. Relationship between multiple plasma biomarkers and vulnerable plaque determined by virtual histology intravascular ultrasound. Circ J 2010; 74: 332-336.

21. Burke AP, Tracy RP, Kologie F, Malcom GT, Zieske A, Kutys R, et al. Elevated C-reactive protein values and atherosclerosis in sudden coronary death: Association with different pathologies. Circulation 2002; 105: 2019-2023.

22. Sano T, Tanaka A, Namba M, Nishibori Y, Nishida Y, Kawarabayashi $\mathrm{T}$, et al. C-reactive protein and lesion morphology in patients with acute myocardial infarction. Circulation 2003; 108: 282-285.

23. Tanaka A, Shimada K, Sano T, Namba M, Samamoto T, Nishida Y, et al. Multiple plaque rupture and C-reactive protein in acute myocardial infarction. J Am Coll Cardiol 2005; 45: 1594-1599.

24. Hong MK, Mintz GS, Lee CW, Kim YH, Lee SW, Song JM, et al. Comparison of coronary plaque rupture between stable angina and acute myocardial infarction: A three-vessel intravascular ultrasound study in 235 patients. Circulation 2004; 110: 928-933.

25. Kashiwagi M, Tanaka A, Kitabata H, Tsujioka H, Matsumoto H, Arita Y, et al. Relationship between coronary arterial remodeling, fibrous cap thickness and high-sensitivity C-reactive protein levels in patients with acute coronary syndrome. Circ J 2009; 73: 1291-1295.

26. Katakami N, Matsuhisa M, Kaneto H, Matsuoka TA, Sakamoto K, Yasuda T, et al. Serum endogenous secretory RAGE level is an independent risk factor for the progression of carotid atherosclerosis in type 1 diabetes. Atherosclerosis 2009; 204: 288-292.

27. Koyama H, Shoji T, Yokoyama H, Motoyama K, Mori K, Fukumoto $\mathrm{S}$, et al. Plasma level of endogenous secretory RAGE is associated with components of the metabolic syndrome and atherosclerosis. Arterioscler Thromb Vasc Biol 2005; 25: 2587-2593.

28. Falcone C, Emanuele E, D'Angelo A, Buzzi MP, Belvito C, Cuccia $\mathrm{M}$, et al. Plasma levels of soluble receptor for advanced glycation endproducts and coronary artery disease in nondiabetic men. Arteroscler Thromb Vasc Biol 2005; 25: 1032-1037.

29. Mahajan N, Malik N, Bahl A, Sharma Y, Dhawan V. Correlation among soluble markers and severity of disease in non-diabetic subjects with pre-mature coronary artery disease. Mol Cell Biochem 2009; 330: $201-209$.

30. Nakamura K, Yamagishi S, Adachi H, Kurita-Nakamura Y, Matsui $\mathrm{T}$, Yoshida T, et al. Elevation of soluble form of receptor for advanced glycation endproducts (sRAGE) in diabetic subjects with coronary artery disease. Diabetes Metab Res Rev 2007; 23: 368 371.

31. Nakamura K, Yamagishi S, Adachi H, Matsui T, Kurita-Nakamura Y, Takeuchi M, et al. Serum levels of soluble form of receptor for advanced glycation endproducts (sRAGE) are positively associated with circulating AGEs and soluble form of VCAM-1 in patients with type 2 diabetes. Microvasc Res 2008; 76: 52-56.

32. Kislinger T, Fu C, Huber B, Qu W, Taguchi A, Du Yan S, et al. N(epsilon)-(carboxymethyl) lysine adducts of proteins are ligands for receptor for advanced glycation endproducts that activate cell signaling pathways and modulate gene expression. J Biol Chem 1999; 274: 31740-31749.

33. Pullerits R, Brisslert M, Jonsson IM, Tarkowski A. Soluble receptor for advanced glycation endproducts triggers a proinflammatory cytokine cascade via beta2 integrin Mac-1. Arthritis Rheum 2006; 54: $3898-3907$. 